rev $\mid$ Psi

Revista de Psicología (UNLP)

https://revistas.unlp.edu.ar/revpsi

\title{
Institucional
}

\section{A propósito de la presentación de la Revista de Psicología, Tercera Época}

\author{
Xavier Oñativia' \\ Correspondencia \\ decanato@psico.unlp.edu.ar \\ Filiaciones institucionales \\ ${ }^{1}$ Facultad de Psicología, Universidad Nacional de \\ La Plata (Argentina)
}

Tenemos la enorme satisfacción de presentarles el número 16 de la Revista de Psicología. A 100 años de la Reforma Universitaria y 60 años de la creación de Carrera de Psicología de la Universidad Nacional de La Plata damos comienzo a la Tercera Epoca de la publicación más tradicional de nuestra casa de estudios.

Toda publicación es la expresión de un proyecto institucional y de un momento histórico-político. En este caso se trata de una propuesta renovada que constituye un nuevo tiempo de la Revista, en íntima relación con una nueva etapa de la vida institucional de nuestra Facultad. Es, por un lado, una vía para profundizar la relación entre la Academia y la Comunidad, acercando recíprocamente saberes y sentidos. Esto es, la producción de conocimiento integral, situado, con compromiso social y al servicio de las necesidades de la población que sostiene la universidad pública con su esfuerzo. Por otra parte, constituye un paso relevante en dos objetivos que nos planteamos: la promoción y apoyo de nuestros investigadores, extensionistas, docentes y estudiantes, y la internacionalización de nuestra Facultad de Psicología.

La decisión de jerarquizar y renovar nuestra revista encuentra un marco propicio a nivel de las autoridades de la Universidad Nacional de La Plata, encabezada por

Editor

Nicolás Alessandroni | Facultad de Psicología, Universidad Autónoma de Madrid (España)
ISSN

2422-572X

Licencia

(c) Copyright: Oñativia, X. Este trabajo se distribuye bajo una licencia de Cultura Libre CC-BY 4.0

Entidad editora

RevPsi es una publicación de la

Facultad de Psicología (Universidad

Nacional de La Plata, Argentina)

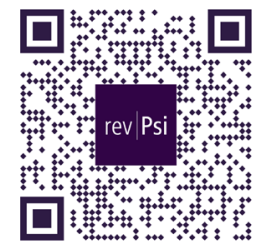

ACCESO ABIERTO DIAMANTE ə 
su presidente Fernando Tauber, quien ha hecho explícita su voluntad política de fortalecer y visibilizar la producción científica de la Universidad. En tal sentido, cabe destacar, entre diversas iniciativas, la creación de un portal de revistas científicas en el ámbito de la Secretaría General, orientado a respaldar y poner en valor el desarrollo de las Facultades y centros de investigación.

A sólo seis meses del inicio de nuestra gestión compartimos con ustedes la inauguración de la Tercera Epoca de la Revista de Psicología. La misma se caracteriza por ser una etapa de apertura editorial, que propone recuperar no sólo la continuidad de su publicación, detenida en el volumen correspondiente al año 2015, sino también la tradición y calidad de los debates e intercambios que caracterizaron sus mejores años.

Con anterioridad a la publicación de este primer número de la Tercera Epoca, la Revista de Psicología no estaba indexada en ninguna base de datos, no empleaba servicios de valor agregado, no seguía estándares de diseño editorial, no informaba con detalle su posicionamiento respecto de las políticas de acceso abierto, no indicaba si adoptaba códigos éticos internacionales, y no informaba políticas de auto-archivo. Por su discontinuidad y la ausencia de muchos requisitos editoriales, no alcanzaba el nivel de revista de grupo 3 según la normativa CONICET. Esto implicaba que en ciertas instancias de evaluación promovidas por la UNLP y CONICET los manuscritos publicados en la Revista no fueran valorados adecuadamente, aunque tuvieran enorme valor académico. Esta realidad contrastaba con los valiosos desarrollos de los docentes, extensionistas, investigadores y becarios de nuestra Facultad. Este primer número de la Tercera Época comienza a corregir el rumbo editorial de la publicación.

No sólo se trata de recuperar lo mejor de nuestra historia editorial, sino también de avanzar hacia una revista contemporánea, sólida y dinámica, con mayor periodicidad que la que traía (anual), que se adecue rápidamente a los requerimientos internacionales, que incorpore los últimos adelantos técnicos, que construya fuertes vínculos con centros de conocimiento del mundo, y que contribuya a poner en valor la producción de conocimiento propia, proyectándola con vigor a los planos nacional e internacional.

Al mismo tiempo, desde una perspectiva de complementariedad y colaboración, nos interesa consolidar espacios de intercambio donde colegas de universidades hermanas, en particular de Latinoamérica, puedan encontrar nuevas posibilidades para difundir sus producciones locales y fortalecer vínculos de intercambio y crecimiento recíproco. En esa dirección se incorpora la publicación de trabajos en portugués, con el objeto de promover un acercamiento estratégico hacia las fuentes académicas de Brasil.

Otro aspecto destacado de esta Tercera Epoca lo constituye la apuesta por la Ciencia Abierta, a tono con los últimos debates internacionales acerca de la difusión del conocimiento. Esto permitirá a nuestra institución ofrecer a sus miembros una plataforma de excelencia y de acceso abierto para la publicación de sus trabajos. 
La propuesta editorial que aquí se presenta implica un compromiso fuerte con la democratización del acceso al conocimiento, no sólo por el modelo de difusión al que suscribe (acceso abierto diamante), sino por el carácter inclusivo del proyecto, que considera la incorporación de nuevos actores a la publicación de primer nivel. Así, se prevé la ampliación de las voces de la comunidad académica, para lo que se considerará especialmente la participación de, por ejemplo, estudiantes (en primera persona, a través de sus propias producciones) y referentes comunitarios.

Ello supone interpelar la idea de que existen ciertos saberes que deberían ostentar un estatus privilegiado en detrimento de otros que serían de menor grado o que merecerían ser expulsados de la academia. Entendemos la importancia de jerarquizar esos otros saberes marginalizados, que yacen en las instancias del trabajo diario donde se desarrolla la profesión (más allá incluso del conocimiento específico de las disciplinas), en el hacer de los técnicos, en las prácticas de los referentes de la comunidad, en la memoria de los pueblos originarios. Se trata de invitarlos a habitar la academia para que en el intercambio y la integración se opere un fortalecimiento de las instancias de enseñanza y aprendizaje.

En el mismo sentido se encuentra otra novedad de esta Tercera Epoca: la incorporación de nuevos formatos de publicación. A los artículos tradicionales de investigación, se sumarán reportes de investigación, dossiers, relatos de experiencias e intervenciones, traducciones, entrevistas, reseñas de libros o eventos científicos, y trabajos de graduación o de integración final de estudiantes de la carrera.

Para dar este salto cuali-cuantitaivo es necesario llevar adelante una tarea planificada y sistemática de mejoramiento de su calidad. A tal efecto, proponemos un ambicioso y exigente plan de acción: trabajar intensamente para que la Revista se publique semestralmente, duplicando la frecuencia anterior, y en un plazo de dos años, logre su indexación en diversas bases de datos y servicios de información, tales como REDIB, Latindex Catálogo, ERIH Plus, Sherpa/Romeo, MIAR y Redalyc, a efectos de que pueda ser incluida en el nivel de revistas de grupo 1 (de acuerdo a la clasificación CONICET).

Quiero agradecer especialmente a quien hemos convocado para tan ardua y esforzada tarea: el Mg. Nicolás Alessandroni, quien asume este gran desafío como Editor y Director de la Revista de Psicología. Es un privilegio contar con su apoyo, talento, imaginación y contracción al trabajo, elementos sin los cuales no se podría alcanzar la elevada meta que nos propusimos. Sus antecedentes en la edición de revistas científicas, su destacada carrera en la investigación, y su inserción en el plano académico internacional nos permiten augurar el mayor de los éxitos para su tarea, que significará un valioso aporte para nuestra Facultad.

En suma, esta Tercera Epoca nos trae una propuesta moderna, innovadora, que incorpora novedades técnicas, conceptuales, ideológicas y políticas, al tiempo que asimila requerimientos y estándares internacionales para las revistas de la mejor calidad. Será un espaldarazo para la producción científica de los investigadores, extensionistas, docentes, becarios y tesistas de la casa, y a la vez la expresión de un 
proyecto institucional comprometido con la defensa de la Universidad Pública, la Salud Pública y los Derechos Humanos.

El proyecto de la Revista de Psicología resulta de una continuidad entre la labor del Area de Publicaciones y el nuevo equipo de dirección y edición de esta Revista. Este movimiento editorial es un componente destacado de los objetivos institucionales para la presente gestión (los que propusimos y asumimos como un compromiso público mediante la Propuesta de lineamientos y acciones para el próximo período de gestión 2018-2022 de la Facultad de Psicología (UNLP)), mediante los cuales esperamos contribuir al crecimiento del conocimiento, de nuestra comunidad académica y de la Facultad en general. Celebramos el inicio de la Tercera Epoca de nuestra histórica publicación y convocamos a quienes deseen acercar sus contribuciones a aprovechar y disfrutar esta propuesta, a hacerla propia.

Xavier Oñativia

Decano

Facultad de Psicología (UNLP) 